\title{
Computer Simulation of the Effect of Copper on Defect Production and Damage Evolution in Ferritic Steels
}

J.M. Perlado, J. Marian, D. Lodi, T. Diaz De La Rubia

This article was submitted to

Materials Research Society Fall 1999 Meeting, Boston, MA, November 29 - December 3, 1999

U.S. Department of Energy

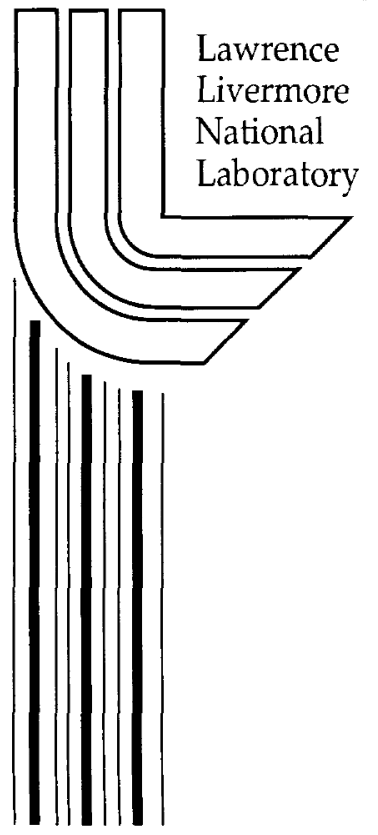

November 28, 1999 



\section{DISCLAIMER}

This document was prepared as an account of work sponsored by an agency of the United States Government. Neither the United States Government nor the University of California nor any of their employees, makes any warranty, express or implied, or assumes any legal liability or responsibility for the accuracy, completeness, or usefulness of any information, apparatus, product, or process disclosed, or represents that its use would not infringe privately owned rights. Reference herein to any specific commercial product, process, or service by trade name, trademark, manufacturer, or otherwise, does not necessarily constitute or imply its endorsement, recommendation, or favoring by the United States Government or the University of California. The views and opinions of authors expressed herein do not necessarily state or reflect those of the United States Government or the University of California, and shall not be used for advertising or product endorsement purposes.

This is a preprint of a paper intended for publication in a journal or proceedings. Since changes may be made before publication, this preprint is made available with the understanding that it will not be cited or reproduced without the permission of the author.

This report has been reproduced directly from the best available copy.

Available electronically at http://www.doe.gov/bridge

Available for a processing fee to U.S. Department of Energy and its contractors in paper from

U.S. Department of Energy Office of Scientific and Technical Information

P.O. Box 62

Oak Ridge, TN 37831-0062

Telephone: (865) 576-8401

Facsimile: (865) 576-5728

E-mail: reports@adonis.osti.gov

Available for the sale to the public from

U.S. Department of Commerce

National Technical Information Service 5285 Port Royal Road Springfield, VA 22161

Telephone: (800) 553-6847

Facsimile: (703) 605-6900

E-mail: orders@ntis.fedworld.gov

Online ordering: http://www.ntis.gov/ordering.htm

OR

Lawrence Livermore National Laboratory

Technical Information Department's Digital Library

http://www.llnl.gov/tid/Library.html 



\title{
COMPUTER SIMULATION OF THE EFFECT OF COPPER ON DEFECT PRODUCTION AND DAMAGE EVOLUTION IN FERRITIC STEELS
}

\author{
J. M. PERLADO* ${ }^{*}$ J. MARIAN* ${ }^{*}$, D. LODI ${ }^{*}$, T. DÍAZ DE LA RUBIA** \\ * Instituto de Fusión Nuclear (DENIM), Universidad Politécnica de Madrid, C/ José Gutiérrez \\ Abascal, 2, 28006-Madrid, Madrid, SPAIN, jaime@denim.upm.es \\ ** Chemistry and Materials Science Directorate, Lawrence Livermore National Laboratory, \\ L-268, Livermore, CA 94550
}

\begin{abstract}
It has long been noticed that the effect of $\mathrm{Cu}$ solute atoms is important for the microstructural evolution of ferritic pressure vessel steels under neutron irradiation conditions. Despite the low concentration of $\mathrm{Cu}$ in steel, $\mathrm{Cu}$ precipitates form inside the $\alpha$-Fe surrounding matrix and by impeding free dislocation motion considerably contribute to the hardening of the material. It has been suggested that $\mathrm{Cu}$-rich clusters and combined $\mathrm{Cu}$ solute atoms-defect clusters that may act as initiating structures of further precipitates nucleate during annealing of displacement cascades. In order to assess the importance of the different mechanisms taking place during collision events in the formation and later evolution of these structures, a detailed Molecular Dynamics (MD) analysis of displacement cascades in a Fe-1.3\% at. Cu binary alloy has been carried out. Cascade energies ranging from 1 to $20 \mathrm{keV}$ have been simulated at temperatures of 100 and $600 \mathrm{~K}$ using the MDCASK code, in which the Ackland-Finnis-Sinclair many-body interatomic potential has been implemented. The behaviour of metastable $\mathrm{Cu}$ selfinterstitial atoms (SIAs) in the form of mixed $\mathrm{Fe}-\mathrm{Cu}$ features is studied as well as their impact on the resulting defect structures. It is observed that above $300 \mathrm{~K}$ generated $\mathrm{Cu}$ SIAs undergo recombination with no substantial effect on the after-cascade microstructure while at $100 \mathrm{~K} \mathrm{Cu}$ SIAs remain sessile and exhibit a considerable binding to interstitial and vacancy clusters. Finally, the effect that the production of vacancies via collision cascades may have on the selfdiffusion of $\mathrm{Cu}$ solute atoms is quantitatively addressed by means of determining diffusion coefficients for $\mathrm{Cu}$ atoms under different microstructural conditions.
\end{abstract}

\section{INTRODUCTION}

As many nuclear power plants approach the end of their licensed operational life, one topic of current concern is the change in the mechanical properties that reactor pressure vessels (RPVs) may suffer after prolonged exposures to neutron irradiation environments. It is well known that pressure vessel steels embrittle under irradiation conditions due to the production of atomic-scale defect aggregates that hinder free dislocation motion resulting in hardening of the material. In addition to hardening caused by radiation produced clusters of defects, there is the contribution of nano-scale features such as $\mathrm{Cu}$ and $\mathrm{Mn}-\mathrm{Ni}$ rich precipitates that form in the core of the material despite the low concentration of these elements in RPV steels [1,2]. Depending on alloy composition, $\mathrm{Cu}$-rich precipitates are the dominant nanofeature in steels containing more than 0.1 at. \% $\mathrm{Cu}[3]$ and this issue has attracted much research using a variety of techniques [4]. While there has been a number of experimental studies concerning the effect of $\mathrm{Cu}$ solute atoms as well as of the precipitates' structure in the microstructural evolution of irradiated steels $[5,6,7]$, computer simulation of the precipitation kinetics has been treated recently $[8,9,10,11]$. This computational research effort has consisted mainly of lattice and kinetic MonteCarlo simulations of the $\mathrm{Cu}$ precipitation during thermal or cascade ageing and 
the interaction of these precipitates with cascade debris, particularly vacancies $[8,11]$. Results of these simulations indicate that both well-formed precipitates and solute atmospheres are formed as a consequence of highly correlated vacancy-solute transport processes and radiationenhanced diffusion [8,12]. Moreover, there is a general belief that vacancy cluster-Cu solute atoms complexes that may act as precipitate precursors are produced during annealing of displacement collision cascades [12]. Other cascade effects of interest such as $\mathrm{Cu}$ SIA production and their interaction with characteristic cascade defect-structures (vacancy and SIA clusters) or more generally, the significance that solute atoms in a dilute substitutional solid solution have in the cascade evolution, are issues that occur in time scales (ps) much shorter than those related with the creation and coalescence of $\mathrm{Cu}$ precipitates (seconds). In this paper, a number of high-energy displacement cascades in a diluted $\mathrm{Fe}-\mathrm{Cu}$ binary alloy at $600 \mathrm{~K}$ and $100 \mathrm{~K}$ has been carried out in order to investigate the process of in-cascade formation of vacancy-Cu complexes and $\mathrm{Cu}$ SIAs. The $\mathrm{Cu}$ content in the solution has been chosen to be $1.3 \%$ at. to enhance the statistics concerning the $\mathrm{Cu}$ atoms and due to the existence of several experimental works where $\mathrm{Fe}-1.34 \% \mathrm{Cu}$ type alloys were employed [7,13].

\section{SIMULATION MODEL}

\section{Molecular Dynamics}

Although, collision events have been thoroughly analyzed with MD in pure metals $[14,15,16]$, except for some specific papers [17], MD simulations in binary alloys have not been sufficiently studied. All the cascade simulations presented in this paper have been performed with the MDCASK code in which the new Fe-Cu potential derived by Ackland [18] from the Finnis-Sinclair many-body formulation [19] has been implemented. Details about the MDCASK code as to potential implementation, integration of the equations of motion, etc. are given elsewhere [20]. The simulations were carried out with periodic boundary conditions at constant volume. The Langevin equation of motion is applied to the atoms of the cell boundaries in order to control the temperature of the crystal.

\section{Starting Assumptions}

As in regular MD cascade simulation procedures, the solid solution was first equilibrated during several $(8 \sim 10)$ picoseconds before the introduction into the system of the primary knock-on atom (PKA). The $\mathrm{Cu}$ atoms were introduced randomly into the bcc $\alpha-\mathrm{Fe}$ matrix up to a proportion of 1.3 at. \%. The effect that the $\mathrm{Cu}$ solute atoms have on the lattice parameter according to Wriedt et al. [21] has also been taken into account in our simulations, i.e. $\Delta \mathrm{a}_{0}=0.94 \times 10^{-3} \AA$ per at. $\% \mathrm{Cu}$ gives $\Delta \mathrm{a}_{0}=0.0012 \AA$, which means that $\mathrm{a}_{\mathrm{o}}=2.867 \AA$ rather than $2.866 \AA$ for the bcc pure $\alpha$-Fe lattice. Although this consideration is expected to have little or no effect on the results, this minute rigid dilation of the lattice may help ease down the additional strain introduced by $\mathrm{Cu}$ solute atoms and $\mathrm{Cu}$ SIAs during cascade ageing and yield more reliable results. Once the crystal was stabilized at the desired temperature, the resulting configuration was taken as starting point for all the cascades of a given energy. In order to get a reasonable statistics as to the number and type of defects produced, up to ten cascades were simulated for each PKA energy corresponding to different crystallographic directions. Both Fe and $\mathrm{Cu}$ PKAs were essayed for each one of the cascade energies in order to facilitate comparison between the effects of both species on atomic-scale damage production. 


\section{RESULTS}

\section{Cascade Analysis}

The total number of cascades simulated for each energy can be seen in Table I. Simulations at $100 \mathrm{~K}$ and $600 \mathrm{~K}$ were performed only for $20 \mathrm{keV}$ cascades since it is for high energies that variable conditions are more meaningful to microstructural evolution. The average number of Frenkel pairs produced in each cascade is also shown in Table I for cascades in the $\mathrm{Fe}-\mathrm{Cu}$ solution and in pure $\alpha-\mathrm{Fe}$. It is noteworthy that the number of defects in pure $\mathrm{Fe}$ is consistently higher than in $\mathrm{Fe}-\mathrm{Cu}$ as if the $\mathrm{Cu}$ atoms in the substitutional solution deadened the expansion of the cascade. A preliminary estimation of this effect can be extracted calculating the volume of the cascade applying the criteria used by Gao and Bacon [22] where this cascade volume is defined as the sphere that contains at least $90 \%$ of the displaced atoms at its maximum expansion. Following this, the radius of such a sphere for a $10 \mathrm{keV}$ cascade $\left(45 \mathrm{a}_{0} \times 45 \mathrm{a}_{0} \times 45 \mathrm{a}_{0}\right.$ box) in the $\mathrm{Fe}-\mathrm{Cu}$ alloy was found to be approximately $12.5 \mathrm{a}_{\mathrm{o}}$ whereas the volume in a pure Fe block in equivalent conditions was $14.2 \mathrm{a}_{0}$. For $5 \mathrm{keV}$ cascades $\left(30 \mathrm{a}_{0} \times 30 \mathrm{a}_{0} \times 30 \mathrm{a}_{0}\right.$ box), the radius in the $\mathrm{Fe}-\mathrm{Cu}$ system is $7.6 \mathrm{a}_{\mathrm{o}}$ while the volume in the equivalent pure Fe block was $\sim 9 \mathrm{a}_{0}$. Although a satisfactory explanation for this behavior may involve other physical factors such as threshold displacement energies or linear energy transport along replacement collision sequences (RCSs), this effect seems to be somewhat an artifact of the interatomic potentials employed. The resulting RCSs are shorter in length giving rise to a lesser production of defects.

Table I: Number of cascades and defect production in the analyzed Fe-Cu alloy. Numbers in parentheses in the fourth column are data for comparison from cascades simulated in pure $\alpha-\mathrm{Fe}$ at $600 \mathrm{~K}$ with the EAM potential [23].

\begin{tabular}{cccccc}
\hline \multirow{2}{*}{ PKA energy $(\mathrm{keV})$} & \multicolumn{2}{c}{ Number of cascades } & & $\begin{array}{c}\text { Average total number } \\
\text { of Frenkel pairs }\end{array}$ & $\begin{array}{c}\text { Average number of } \\
\text { Cu SIAs generated }\end{array}$ \\
\cline { 2 - 3 } & $600 \mathrm{~K}$ & $100 \mathrm{~K}$ & & $8(10)$ & 0 \\
2 & 10 & - & $12(19.5)$ & 0 \\
10 & 10 & - & $27(35)$ & 0.5 \\
20 & 10 & - & $53 / 56(58)$ & $1.8 / 2.1$ \\
\hline
\end{tabular}

As reported by some authors [16,17], vacancy clustering in bcc metals is limited. In addition to this intrinsic feature, vacancies are not left to freely rearrange themselves into clusters or collapsed plates due to the effect of $\mathrm{Cu}$ solute atoms that, if sufficient annealing is allowed, form shells around the vacancy-rich core. This indeed has to do with the enhanced diffusion that $\mathrm{Cu}$ atoms close to the core of the cascade suffer via the vacancy mechanism. Some of the $10 \mathrm{keV}$ cascades at $600 \mathrm{~K}$ were granted 1.15 additional ns of relaxation to check if this forced diffusion could affect the redistribution of $\mathrm{Cu}$ solute atoms and the vacancy clustering fraction. Results can be observed in Figure 1, where weak clouds of $\mathrm{Cu}$ atoms tend to form around the cascade core, as anticipated by Odette et al. [13]. A quantitative measure of this effect can be extracted by calculating the moment of inertia, $I$, of the $\mathrm{Cu}$ atoms in figures 1 (a) and 1 (b) $\left(I=\Sigma\left(\mathbf{r}_{C u}-\mathbf{r}_{g}\right)^{2} / N_{C u}\right.$, where $\mathbf{r}_{g}$ is the center of mass of the cascade vacancies and $N_{C u}$ the total number of $\mathrm{Cu}$ atoms). The value for the initial configuration is $I \approx 232 \mathrm{a}_{0}{ }^{2}$ whereas for the final configuration after $1.15 \mathrm{~ns}, I \approx 228 \mathrm{a}_{0}{ }^{2}$. With respect to the vacancy clustering fraction, the Ackland-Finnis-Sinclair potential yields a binding energy $\left(e_{b}\right)$ of $0.14 \mathrm{eV}$ for the $1^{\text {st }}$ nearest neighbor ( $1 \mathrm{nn}$ ) divacancy in pure $\mathrm{Fe}$, and a value of $0.19 \mathrm{eV}$ for the $2^{\text {nd }}$ nearest neighbor 
( $2 \mathrm{nn}$ ) divacancy. Beyond this distance the vacancies are not bound at all $\left(\mathrm{e}_{\mathrm{b}}=0\right)$ so our criterion for vacancy clustering is that they be within $2 \mathrm{nn}$ distances. Following this, for our $\mathrm{Fe}-\mathrm{Cu} 20$ $\mathrm{keV}$ cascades, we get a value of 0.25 at $600 \mathrm{~K}$ and 0.22 at $100 \mathrm{~K}$ for the vacancy clustering fraction, while, for instance, Stoller [24], for pure Fe, obtained values of 0.37 and 0.50 respectively, using the $2 \mathrm{nn}$ clustering criterion. Nevertheless, there is probably some potentialdependence contribution to this difference. These numbers, however, indicate that, even though vacancies are more strongly bound to each other $\left(\mathrm{e}_{\mathrm{b}}=0.14 \mathrm{eV}\right)$ than to $\mathrm{Cu}$ atoms $\left(\mathrm{e}_{\mathrm{b}}=0.09 \mathrm{eV}\right)$, the effect of the solute over the clustering tendency of the vacancies is to hinder it.

\section{Cu Self-Interstitials}

As anticipated before, $\mathrm{Cu}$ SIAs are metastable defects that appear as final links of RCSs in displacement cascades. When found isolated, $\mathrm{Cu}$ interstitials are observed forming mixed $\mathrm{Fe}$ $\mathrm{Cu}$ split dumbbells (formation energy, $\mathrm{e}_{\mathrm{f}}=6.18 \mathrm{eV}$ ). The activation energy for the $\mathrm{Cu}$ atom to take the split lattice position (recombine) has been calculated to be approximately $0.16 \mathrm{eV}$, i.e. forcing the formation of a pure Fe-Fe dumbbell via the interstitialcy mechanism. This means that in the cascades at $600 \mathrm{~K}, \mathrm{Cu}$ SIAs undergo recombination quickly and have no further significant effect on the crystal lattice. However, at $100 \mathrm{~K} \mathrm{Fe}-\mathrm{Cu}$ dumbbells remain sessile and their average lifetime has been extrapolated to be as long as $0.5 \mu \mathrm{s}$.

On the other hand, in some cascades at $600 \mathrm{~K} \mathrm{Cu}$ interstitials were found in the form of $<111>$ crowdions $\left(e_{\mathrm{f}}=6.40 \mathrm{eV}\right)$ forming small dislocation loops with a considerable binding energy $\left(\mathrm{e}_{\mathrm{b}}=1.15 \mathrm{eV}\right)$. These $\mathrm{Cu}$ interstitials, however, did not seem to be any obstacle to the further propagation of the loops.

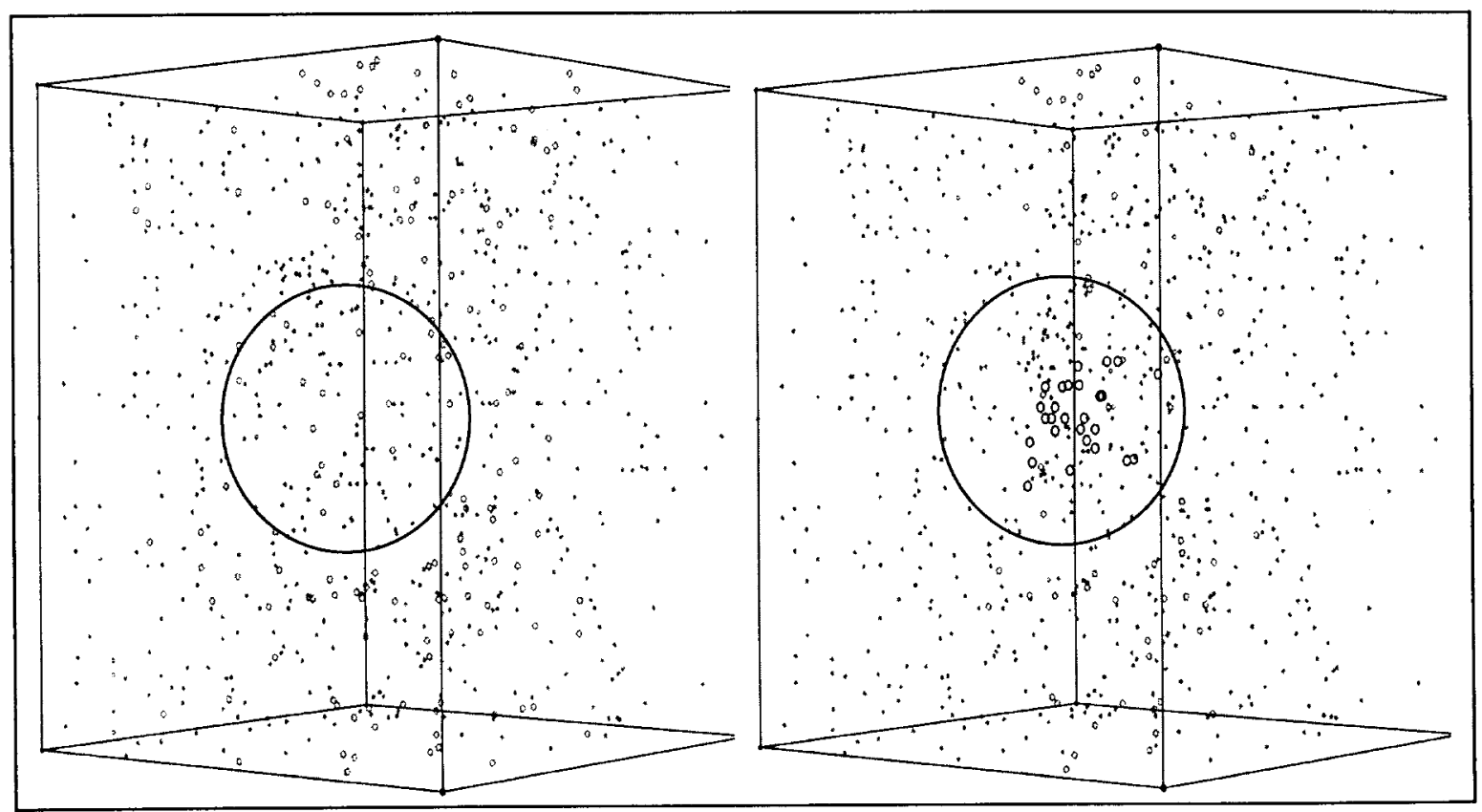

Figure 1. (a) Initial atomic configuration of the computation box. Only $\mathrm{Cu}$ solute atoms are shown (gray dots). (b) Final distribution of $\mathrm{Cu}$ atoms and vacancies (big circles) $1.15 \mathrm{~ns}$ after the $10 \mathrm{keV}$-PKA event. Note the increased density of solute in the encircled area (cascade core). 


\section{Enhanced Diffusion Kinetics}

The combination of excess vacancies and excited $\mathrm{Cu}$ solute atoms hastens the process of solute clustering and gives rise to atomic configurations like that shown in Fig. 1 (b). A way to quantify this enhanced $\mathrm{Cu}$ solute atom-migration is calculating the self-diffusion coefficient, $D$, via MD simulations. In principle, a coarse estimation of $D$ (vacancy mechanism) can be obtained through the following expression:

$$
D=C \cdot \omega \cdot N_{v} \cdot \mathrm{a}_{0}^{2}
$$

where $C$ is a constant that includes the nature of the $1 \mathrm{nn}$ jumps in the bcc lattice, $\omega$ is the jump frequency, $a_{0}$ the lattice parameter and $N_{v}$ is the probability to find a vacancy in a given lattice position, i.e. the percentage of vacancies in the crystal. As to $\omega$, it is ordinarily taken as $\omega=$ $v \cdot \exp \left(-E_{m} / K T\right)$, where $E_{m}$ is the energy required to move an atom to the saddle point position, $K$ the Boltzmann's constant, $T$ the absolute temperature of the crystal and $v$ is a typical

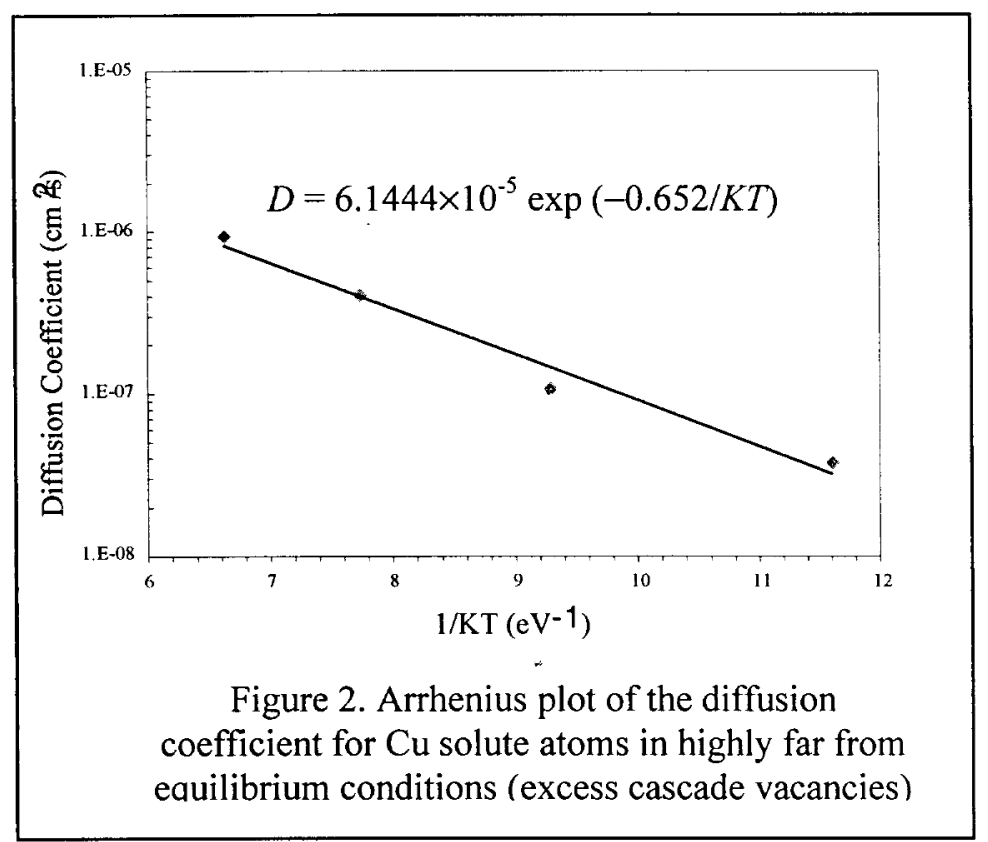
vibration frequency of the material $\left(\sim 10^{13} \mathrm{~Hz}\right)$. We have calculated the Cu-vacancy interchange energy by a static relaxation calculation and computed a value of $0.739 \mathrm{eV}$, similar to the number employed by Soisson et al. $(0.69 \mathrm{eV})$ [9], but quite different to the one obtained by Ackland et al. $(0.60 \mathrm{eV})[19]$. In a system at equilibrium conditions $N_{v}$ is usually taken as $N_{v}=$ $N_{o} \cdot \exp \left(-E_{f} / K T\right), E_{f}$ being the vacancy formation energy. Hence, in the $1000-1500 \mathrm{~K}$ temperature interval, $N_{v}$ ranges between $2 \times 10^{-9}$ and $2 \times 10^{-6}$, having taken $E_{f}=1.7$ $\mathrm{eV}$. However, during cascade ageing highly non-equilibrium conditions are found and the increased local strain due to the excess vacancies tends to be counterbalanced by the diffusion of energetic $\mathrm{Cu}$ atoms. Under these extreme conditions, it is not exaggerated to consider $N_{v} \approx 0.01$ in a domain around the vacancy-rich core of the cascade. We have calculated the temperature dependence of $D$ assuming an Arrhenius behaviour:

$$
D=D_{o} \cdot \exp \left(-E_{m} / K T\right)
$$

where $D$ has been calculated for four different temperatures $\left(0.55 \mathrm{~T}_{\mathrm{m}}, 0.70 \mathrm{~T}_{\mathrm{m}}, 0.85 \mathrm{~T}_{\mathrm{m}}\right.$ and $0.95 \mathrm{~T}_{\mathrm{m}}$ ) in a $\mathrm{Fe}-1.3 \%$ at. $\mathrm{Cu}$ solution with $1 \%$ concentration of vacancies (figure 2 ). Atoms were allowed to evolve during 0.75 ns and then $D_{C u}$ was estimated using:

$$
D_{C u}=\frac{1}{6} \frac{d}{d t}\left\langle R_{C u}^{2}(t)\right\rangle
$$


From (2) and (3) we obtained: $D_{C u}=6.144 \times 10^{-5} \cdot \exp (-0.652 / K T)\left(\mathrm{cm}^{2} \cdot \mathrm{s}^{-1}\right)$. This means that, for $T=1500 \mathrm{~K}, D_{C u} \sim 3.96 \times 10^{-7} \mathrm{~cm}^{2} \cdot \mathrm{s}^{-1}$ which is reasonably close to the value deduced from (1) at $1500 \mathrm{~K}$ and $N_{v}=0.01\left(4.80 \times 10^{-7} \mathrm{~cm}^{2} \cdot \mathrm{s}^{-1}\right)$.

\section{CONCLUSIONS}

Preliminary results of the effects of $\mathrm{Cu}$ solute atoms at low concentration in $\mathrm{Fe}$ in displacement cascades have been presented. The development of the thermal spike is restrained by the containment effect of $\mathrm{Cu}$ solute atoms. The formation of precursor $\mathrm{Cu}$ solute atomclouds as well as of $\mathrm{Cu}$-vacancy clusters has been demonstrated as a consequence of cascade enhanced diffusion kinetics. Further work in order to improve the statistics as to cascade defects and diffusion parameters determination is under progress.

\section{ACKNOWLEDGEMENTS}

This work has been performed at DENIM within the VENUS Research Project framework under contract P970530432 (CSN/UNESA Coordinated Research Programme) and under the auspices of the U.S. Department of Energy by LLNL under contract W7405-ENG-48.

\section{REFERENCES}

[1] G. E. Lucas, G. R. Odette, R. Maiti and J. W. Sheckherd in Influence of Radiation on Materials Properties: $13^{\text {th }}$ International Symposium, Part II, edited by F. A. Garner, C. H. Genager and N. Igata (ASTM-STP 956, ASTM, Philadelphia, PA, 1987) p. 379

[2] S. B. Fisher and J. T. Buswell, Int. J. Pressure Vessel Piping 27, 91 (1987)

[3] G. R. Odette in Microstructure of Irradiated Materials, edited by I. M. Robertson, L. E. Rehn, S. J. Zinkle and W. J. Phytian (Mater. Res. Soc. Proc. 373, Pittsburgh, PA, 1995) p. 137

[4] J. T. Buswell, P. J.Bischler, S. T. Fenton, A. C. Ward and W. J. Phytian, J. Nucl. Mater. 205, 198 (1993)

[5] P. M. Rice and R. E. Stoller, J. Nucl. Mater. 244, 219 (1997)

[6] G. M. Worrall, J. T. Buswell, C. A. English, M. G. Hetherington and G. D. Smith, J. Nucl. Mater. 148, 107 (1987)

[7] A. C. Nicol, M. L. Jenkins and M. A. Kirk in: Microstructural Processes in Irradiated Materials, edited by S. J. Zinkle, G. E. Lucas, R. C. Ewing and J. S. Williams (Mater. Res. Soc. Proc. 540, Warrendale, PA, 1998) p. 409

[8] F. Soisson, A. Barbu and G. Martin, Acta Mater. 44, 3789 (1996)

[9] C. L. Liu, G. R. Odette, B. D. Wirth and G. E. Lucas, Mat. Sci. Eng. A 238, 202 (1997)

[10] B. D. Wirth and G. R. Odette in: Microstructural Processes in Irradiated Materials, edited by S. J. Zinkle, G. E. Lucas, R. C. Ewing and J. S. Williams (Mater. Res. Soc. Proc. 540, Warrendale, PA, 1998) p. 637

[11] C. Domain, C. S. Becquart, J. C. Van Duysen in Microstructural Processes in Irradiated Materials, edited by S. J. Zinkle, G. E. Lucas, R. C. Ewing and J. S. Williams (Mater. Res. Soc. Proc. 540, Warrendale, PA, 1998) p. 643

[12] G. R. Odette and B. D. Wirth, J. Nucl. Mater. 251, 157 (1997)

[13] T. N. Lê, A. Barbu, D. Liu and F. Maury, Scripta Metall. 26, 771 (1992)

[14] T. Díaz de la Rubia and M. W. Guinan, Mater. Res. Forum 97-99, 23 (1992)

[15] A. F. Calder and D. J. Bacon, J. Nucl. Mater. 207, 25 (1993)

[16] D. J. Bacon and T. Díaz de la Rubia, J. Nucl. Mater. 216, 275 (1994)

[17] H. F. Deng and D. J. Bacon, Phys. Rev. B 53, 11376 (1996)

[18] G. J. Ackland, D. J. Bacon, A. F. Calder and T. Harry, Philos. Mag. A 75, 713 (1997)

[19] M. W. Finnis and J. E. Sinclair, Phil. Mag. A 50, 45 (1984)

[20] T. Díaz de la Rubia and M. W. Guinan, Mater. Res. Forum 174, 151 (1990)

[21] H. A. Wriedt and L. S. Darken, Trans. Metals. Soc. AIME 218, 30 (1960) 
[22] F. Gao and D. J. Bacon, Phil. Mag. A, 71, 65 (1995)

[23] R. A. Johnson and D. J. Oh, J. Mater. Res. 4, 1195 (1989)

[24] R. E. Stoller in: Microstructural Processes in Irradiated Materials, edited by S. J. Zinkle, G. E. Lucas, R. C. Ewing and J. S. Williams (Mater. Res. Soc. Proc. 540, Warrendale, PA, 1998) p. 679 
